\title{
MAJOR DEPRESSIVE DISORDER REVEALING CADASIL DISEASE: CASE REPORT
}

\author{
R. Felhi' ${ }^{1}$ A. Bouallagui', M. Mlika' , O. Moula ${ }^{1}$, R. Ghachem ${ }^{1}$ \\ ${ }^{1}$ Razi Hospital, Psychiatry B, Tunis, Tunisia
}

\section{Introduction:}

Cerebral autosomal dominant arteriopathy with subcortical infarcts and leukoencephalopathy (CADASIL) is an inherited cerebrovascular disease caused by a point mutation in the Notch3 gene localized on chromosome 19p13.1 (1).It is characterized by migraine headaches, transient ischemic attacks, strokes, cognitive decline, and dementia. Mood disturbances are

reported in $10 \%$ to $20 \%$ of patients, most often in association with cognitive alterations (2) .

\section{Case presentation:}

Ms M is a 39-year-old woman with family history of migraine and known past medical history of atrial fibrillation and multiple surgeries: cervicobrachial syndrome, carpal tunnel syndrome and breast and thigh adenofibroma but with no past psychiatric history. She consulted to the outpatient psychiatry unit for insomnia and loss of appetite. Ms M reported depressed mood,

social withdrawal, isolation, anhedonia, insomnia, fatigue, loss of concentration, and anxiety for a month. She also complained about chronic headaches, fainting and loss of consciousness occurring for four years.

Neurological examination did not show any abnormalities. Magnetic resonance imaging of the head showed no acute intracranial events. However, it showed frontoparietal and periventricular white matter lesions matching CADASIL. For the depressive disorder, venlafaxine was started and titrated to $75 \mathrm{mg}$ daily. For

the neurological symptoms, she received $250 \mathrm{mg}$ of acetylsalicylic acid daily. Ms M showed improvement in her depressed mood, loss of appetite and headaches. No significant improvement in anxiety, insomnia and loss of concentration was noticed.

\section{Discussion :}

CADASIL is rare hereditary disorder; its prevalence is at least 1.98 per 100,000 adults (3). Clinically, the disease is characterized by a variable combination of migraine, recurrent transient ischemic attack or lacunar strokes, cognitive decline, mood disturbances, and epilepsy (4-7).

Cerebral magnetic resonance imaging (MRI) abnormalities in CADASIL includes hyper-intensities seated in the cerebral white matter of the periventricular

and subcortical regions on $\mathrm{T} 2$-weighted or fluid attenuated inversion recovery (FLAIR) sequences and

lacunar infarcts (8-12). The presence of granular osmiophilic material (GOM) in the dermal vasculature in skin biopsy is pathognomonic but suffers low sensitivity $(13,14,15)$. Mood disorders are said to occur in $24 \%$ of cases, with the vast majority of these patients suffering from major depression (2). CADASIL presents with mood disturbance in up to $9 \%$ of cases (5), usually depression (4), but sometimes also bipolar disorder (16).

The cause of mood disturbance is not clear. However, studies have proven that subjects with CADASIL diagnosed with depression had greater white matter lesion severity and significantly more lacunes then those not meeting the criteria for depressive disorder (17).

\section{Conclusion:}

Mood disorders are frequent but sometimes, can be symptoms of non-psychiatric disorders especially neurological diseases. A normal physical examination does not rule out neurological aetiologies, therefore, further investigations especially neuroimaging are often required when family or personal medical history of neurological disorder are found.

\section{References}

1.JOUTEL A, CORPECHOT C, DUCROS A et al. Notch3 mutations in CADASIL, a hereditary adult-onset condition causing stroke and dementia. Nature 1996,383:707-10 2.VALENTI R, POGGESI A, PESCINI F et al. Psychiatric disturbances in CADASIL : a brief review. Acta Neuro SCand 2008; 118:291.295

3.RAVZI S, DAVIDSON R, Bone I et al. The prevalence of CADASIL in the west of Scotland. J NeuroI Neurosurg Psych2005; 76:739-741

4.CHABRIAT H, VAHEDI K, IBA-ZIZEN MT et al. Clinical spectrum Of CADASIL: a study Of 7 families. Cerebral autosomal dominant arteriopathy with subcortical infarcts and leukoencephalopathy. Lancet 1995;346:934-9.

5.DESMOND IDW, MORONEY JT, LYNCH T, CHAN S, CHIN SS, MOHR JP. The natural history of CADASIL: a pooled analysis of previously published cases. Stroke 1999; 30:1230-3. 6.DICHGANS M. Cerebral autosomal dominant arteriopathy with subcortical infarcts and leukoencephalopathy: phenotypic and mutational spectrum. J Neurol Sci 2002;

7.SINGHAL S, BEVAN S, BARRICK T, RICH P, MARKUS HS. The influence Of genetic and cardiovascular risk factors on the CADASIL phenotype. Brain 2004; 127:231-8.

8.CHABRIAT H, LEVY C, TAILLIA H et al. Patterns of MRI lesions in CADASIL. Neurology 1998;51:452-7.

9.YOUSRY TA, SEELOS K, MAYER M et al. Characteristic MR lesion pattern and correlation of Tl and T 2 lesion volume with neurologic and neuropsychological findings in cerebral autosomal dominant arteriopathy With subcortical infarcts and leukoencephalopathy (CADASI L). AJNR Am J Neuroradiol 1999;20:91-100.

10.AUER IDP, B, GOSSL C, ELBEL G, GASSER T, DICHGANS M., Differential lesion patterns in CADASIL and sporadic subcortical arteriosclerotic encephalopathy: MR imaging study With statistical parametric group comparison. Radiology 2001;218:443-51.

11.O'SULLIVAN M, JAROSZ JM, MARTIN RJ, DEASY N, POWELL JF, MARKUS HS. MRI hyperintensities of the temporal lobe and external capsule in patients With CADASIL. Neurology 2001;56:628-34.

12.SINGHAL S, RICH P, MARKUS HS. The spatial distribution of MR imaging abnormalities in cerebral autosomal dominant arteriopathy With subcortical infarcts and leukoencephalopathy and their relationship to age and clinical features. AJNR Am J Neuroradiol 2005;26:2481-7.

13.CERONI M, POLONI TE, TONIETTI S et al. Migraine With aura and white matter abnormalities: Notch3 mutation. Neurology 2000;54: 1869-71.

14.TUOMINEN S, JUVONEN V, AMBERLA K et al. Phenotype of a homozygous CADASIL patient in comparison to 9 age- matched heterozygous patients With the same R133C Notch3 mutation.Stroke 2001;32:1767-74.

15.EBKE M, DICHIGANS M, BERGMANN M et al. CADASIL : skin biopsy allow diagnosis in early stages. Acta Neurol Scand 1997; 95: $351-357$. 16.KUMAR MAHR G. CADASIL presenting as bipolar. Psychosomatics 1997; 38:397-398.

17.PARK JH, JEON B-H, LEE JS, et al. CADASIL as a useful medical model and genetic form of vascular depression. Am J Geriatr Psychiatry. 2016. 